\title{
ERBB2 Protein Overexpression
}

National Cancer Institute

\section{Source}

National Cancer Institute. ERBB2 Protein Overexpression. NCI Thesaurus. Code C36639.

A molecular abnormality indicating the presence of an abnormally high level of the receptor tyrosine-protein kinase erbB-2 protein. 